Water intake with a pushbutton system and a single meal a day during gestation were found to be insufficient. The supply of a larger amount of water (minimum $18 \mathrm{l} /$ day during gestation) with two meals a day improved the motricity of the animals. The sows being more active had less difficulties at farrowing, milk secretion was improved and piglets were more vigourous. During lactation, the water intake of sows was higher (minimum 24 l/day) which led to an increased feed intake. The mortality rate of piglets was reduced. The number of weaned piglets was higher and they were heavier ( 1 more $\mathrm{kg}$ ).

After weaning, a larger number of sows exhibited grouped oestrus. Reproduction disorders were less frequent. It was concluded that changing the feeding and drinking technique was associated with an improved behaviour of the sows and a better sanitary status resulting in a better efficiency.

\title{
Flooring characteristics and foot lesions in sows and piglets. Influence on performance and nature, frequency and severity of lesions
}

\author{
P. QUEMERE ${ }^{(1)}$, G. DEGROOTE ${ }^{(1)}$, S. DEGROOTE ${ }^{(1)}$, \\ J. STOFFAES ${ }^{(2)}$, F. WILLEQUET ${ }^{(1)}$ \\ (1) S.E.R.E.P.- I.S.A.B., rue Pierre-Waguet, 60026 Beauvais \\ (2) Cabinet Vétérinaire Conseil, 6, rue Pellieux, 80250 Ailly-sur-Noye
}

\begin{abstract}
A study was made to determine the influence of flooring on the performance of sows and suckling piglets and on the characteristics of foot and body lesions and their variations with time. Data concerned 1118 litters belonging to 102 batches observed over a six-year period (1981-1986). In terms of performance, straw-covered concrete floors seemed to be more favourable to the sows, whereas in piglets the best results were obtained with metallic slatted floor $(+9$ p. 100 growth, -2 p. 100 losses). All the sows kept on partly slatted concrete floor during the service-pregnancy period entered the farrowing house with foot lesions (fissure and erosion of the horn) all the more frequent as the litter order was high. During lactation, foot lesions were less frequent but the number of udder and teat injuries was higher. At 8 days of age, the proportion of intact piglets was higher on straw-covered floor than on slatted floor $(27.5$ and 17 p. 100 , respectively). This difference was more marked at weaning (65 versus 19 p. 100). Lesions were variable and concerned heels and wrists. Their incidence and severity were higher on plastic slatted floor. However, their effect on performance could not be demonstrated. After weaning, straw bedding prevented lesions in $60 \mathrm{p}$. 100 of piglets. This protection was reduced on slatted floor (5-times lower). On concrete slatted floor lesions mainly concerned heels and were more severe. During the fattening period, full concrete slatted floor provoked an important erosion of the claws. Frequency of lesions recorded at slaughter depended on that measured at the end of the postweaning period.
\end{abstract}

\section{Impact of new technologies on the control of infectious diseases in the pig}

\author{
H. LAUDE
}

Institut National de la Recherche Agronomique. Station de Recherches de Virologie et d'Immunologie, route de Thiverval, 78850 Thiverval-Grignon

Available technologies mainly derived from cell fusion and DNA recombination have great implications in the control of infectious diseases in animal species, including the pig. Together with a short description of the relevant techniques, this review provides several examples of existing or 
potential applications in the field of diagnosis and vaccination. The use of monoclonal antibodies in research and survey laboratories is now widespread concerning viruses of the classical and African swine fever, Aujeszky's disease, Transmissible gastroenteritis and is extending to bacteriology (Salmonella, Mycoplasma). Nucleic acid probes, presently used as research tools, might also be applied to routine detection of infectious agents. Genetic engineering has allowed the development of several new strategies for immunoprophylaxis : synthetic peptides, recombinant antigens, non-pathogenic live vectors, attenuation by gene deletion. So far, the only commercialised recombinant vaccine is against $\mathrm{E}$. coli-enterotoxicosis in the piglet. Designing of recombinant attenuated strains of pseudorabies virus is in rapid progress. The possibility to differentiate vaccinated from infected animals will be one of the major advantages of the future vaccines.

\title{
Development of an Elisa test to differentiate vaccinated from pseudorabies infected animals
}

\author{
M. ELOIT $^{(1)}$, D. FARGEAUD ${ }^{(2)}$, Ph. VANNIER ${ }^{(3)}$, B. TOMA ${ }^{(1)}$ \\ (1) Ecole Nationale Vétérinaire d'Alfort, Chaire des Maladies contagieuses, \\ 7, avenue du Général-de-Gaulle, 94704 Maisons-Alfort Cedex \\ (2) Rhône Mérieux, I.F.F.A. Mérieux, 254, rue Marcel-Mérieux, 69007 Lyon \\ (3) Ministère de l'Agriculture, Station de Pathologie Porcine, B.P. 9, 22440 Ploufragan
}

The use of two monoclonal antibodies specific of glycoprotein GI and GIII of pseudorabies virus (PRV) led to the development of a competitive Elisa test allowing to differentiate animals infected with PRV from those vaccinated with strains Bartha, NIA4 or Norden. A post-vaccinal serologic response was detectable three to four weeks after vaccination. After virulent challenge of these vaccinated pigs, an infectious serologic response was revealed two weeks after the challenge.

\section{Vaccination trials using the dermic route in the pig}

\author{
A. BRUN ${ }^{(1)}$, Ph. VANNIER ${ }^{(2)}$ \\ (1) Rhône Mérieux, Laboratoire I.F.F.A., 254, rue Marcel-Mérieux, \\ B.P. 700969732 Lyon Cedex 07
}

(2) Station de Pathologie Porcine, B.P. 9, 22440 Ploufragan

Vaccination is necessary to prevent certain diseases in fattening pigs. Vaccination conditions are often difficult and some vaccines are badly tolerated when injected via the intramuscular route. For that reason, vaccination trials were carried out in the pig using the dermic route. Two vaccines against Aujeszky's disease were used : a live modified virus vaccine and an inactivated vaccine prepared from viral glycoprotein. Both vaccines were tested in pigs vaccinated via the dermic route, then challenged with an Aujeszky's disease virus. Immunity results are presented and discussed. 